\title{
The prognostic value of postoperative blood glucose in non-diabetic patients with rheumatic heart disease
}

\author{
Wan-zi Hong ${ }^{1 \dagger}$, Yu Wang ${ }^{1 \dagger}$, Hongjiao $\mathrm{Yu}^{2 \dagger}{ }^{2}$, Xue-biao Wei ${ }^{3}$, Danqing $\mathrm{Yu}^{1}$, Chun-xiang Zhang ${ }^{4}$, Ning Tan ${ }^{{ }^{*}}$ and
} Lei Jiang $3^{3^{*}}$

\begin{abstract}
Background: Blood glucose $(\mathrm{BG})$ is a risk factor of adverse prognosis in non-diabetic patients in several conditions. However, a limited number of studies were performed to explore the relationship between postoperative BG and adverse outcomes in non-diabetic patients with rheumatic heart disease (RHD).

Methods: We identified 1395 non-diabetic patients who diagnosed with having RHD, and underwent at least one valve replacement and preoperative coronary angiography. BG was measured at admission to the intensive care unit (ICU) after surgery. The association of postoperative BG level with in-hospital and one-year mortality was accordingly analyzed.

Results: Included patients were stratified into four groups according to postoperative BG level's (mmol/L) quartiles: Q1 (<9.3 mmol/L, $n=348), Q 2(9.3-10.9 \mathrm{mmol} / \mathrm{L}, n=354), \mathrm{Q} 3(10.9-13.2 \mathrm{mmol} / \mathrm{L}, n=341)$, and Q4 $(\geq 13.2 \mathrm{mmol} / \mathrm{L}, n=352)$. The in-hospital death $(1.1 \%$ vs. $2.3 \%$ vs. $1.8 \%$ vs. $8.2 \%, P<0.001)$ and MACEs $(2.0 \%$ vs. $3.1 \%$ vs. $2.6 \%$ vs. $9.7 \%, P<0.001)$ were significantly higher in the upper quartiles. Postoperative $B G>$ $13.0 \mathrm{mmol} / \mathrm{L}$ was the best threshold for predicting in-hospital death (area under the curve $(A \cup C)=0.707$, 95\% confidence interval $(\mathrm{Cl}): 0.634-0.780, P<0.001)$. Multivariate logistic regression analysis indicated that postoperative $B G>13.0 \mathrm{mmol} / \mathrm{L}$ was an independent predictor of in-hospital mortality (adjusted odds ratio $(\mathrm{OR})=3.418,95 \% \mathrm{Cl}: 1.713-6.821, P<0.001)$. In addition, Kaplan-Meier curve analysis showed that the risk of one-year death was increased for a postoperative BG $>13.2$ (log-rank $=32.762, P<0.001$ ).
\end{abstract}

Conclusion: Postoperative $B G$, as a routine test, could be served as a risk measure for non-diabetic patients with RHD.

Keywords: Rheumatic heart disease, Valve replacement surgery, Blood glucose, In-hospital death

\section{Novelty statement}

Blood glucose is critical for patients undergoing surgery. This study aimed to investigate the effects of postoperative blood glucose and determine whether it could be a valuable factor for non-diabetes patients of rheumatic heart disease undergoing valve replacement surgery, at last, 1395 non-diabetic patients were included in this study, and postoperative BG was shown to be served as a risk-stratified measure for non-diabetic patients with RHD.

\footnotetext{
* Correspondence: ningtan888@yeah.net; jianglei@smu.edu.cn

tWan-zi Hong, Yu Wang and Hongjiao Yu are considered as co-first authors.

'Department of Cardiology, Guangdong Cardiovascular Institute, Guangdong Provincial People's Hospital, Guangdong Academy of Medical Sciences, Guangzhou 510080, China

${ }^{3}$ Guangdong Provincial Geriatrics Institute, Guangdong Provincial People's Hospital, Guangdong Academy of Medical Sciences, Guangzhou 510080, China

Full list of author information is available at the end of the article
}

\section{Background}

Rheumatic heart disease (RHD) is an abnormal autoimmune response caused by group A Streptococcus (GAS) bacterium. As a major burden in developing countries, RHD affects $>34$ million people, causing $>345$, 000 deaths, and 10 million disability-adjusted life years (DALYs) lost per year [1]. Valve replacement surgery

(c) The Author(s). 2019 Open Access This article is distributed under the terms of the Creative Commons Attribution 4.0 International License (http://creativecommons.org/licenses/by/4.0/), which permits unrestricted use, distribution, and reproduction in any medium, provided you give appropriate credit to the original author(s) and the source, provide a link to the Creative Commons license, and indicate if changes were made. The Creative Commons Public Domain Dedication waiver (http://creativecommons.org/publicdomain/zero/1.0/) applies to the data made available in this article, unless otherwise stated. 
can effectively improve the patients' quality of life. However, that surgical method wouldn't be beneficial for all RHD patients, especially for aged patients [2]. Therefore, it is imperative to find effective predictors to find out these patients and pay more attention to improve postoperative survival.

Diabetes mellitus is a metabolic disease characterized by chronic hyperglycemia, and that is a worldwide public health problem, as well as a serious threat to human health. Currently, the prevalence of diabetes has dramatically increased. Compared with non-diabetic patients, diabetes can affect all the vital organs of the body, so that the risk of heart, brain, and peripheral vascular diseases was significantly increased [3]. In patients with New Delhi metallo-beta-lactamase (NDM), the risk of adverse events was linked to hyperglycemia [4]. A previous study has shown that preoperative hyperglycemia is an independent predictor of 30-day and 3-month mortality in valve replacement [5]. Therefore, blood glucose is important for patients with RHD. However, as a postoperative routine examination, a small number of studies have focused on postoperative blood glucose. Therefore, this study aimed to investigate the effects of postoperative blood glucose and determine whether it could be a valuable factor for RHD after valve replacement surgery for patients without diabetes.

\section{Methods}

\section{Study design and population}

A total of 1858 patients with RHD were consecutively screened in the Guangdong General Hospital (Guangzhou, China) between March 2009 and July 2013. All the patients with RHD received at least 1 valve replacement and preoperative coronary angiography. RHD was diagnosed according to previous acute rheumatic fever and/or symptom of precordial abnormalities and presence of heart murmur, and more importantly based on echocardiographic findings. Patients who committed suicide in hospital, or did not have a postoperative glucose data, or have diabetes were excluded from this study. Subjects with $\mathrm{HbA1c} \geq 6.5 \%$ or fasting plasma glucose (FGB) $\geq 7.0 \mathrm{mmol} / \mathrm{L}$ were excluded as well. Finally, 1395 patients were eligible to be included in our analysis (Fig. 1). The primary endpoint was in-hospital all-cause mortality except for suicide during hospitalization, and the secondary endpoint was one-year mortality after operation and in-hospital major adverse clinical events (MACEs), which were defined as composite end points, such as death, renal failure with dialysis, and stroke.

This study was approved by the Ethics Committee of the Guangdong Provincial People's Hospital, accompanying with a waiver of informed consent due to the retrospective study design. Oral informed consent was obtained from the patients or their close relatives by
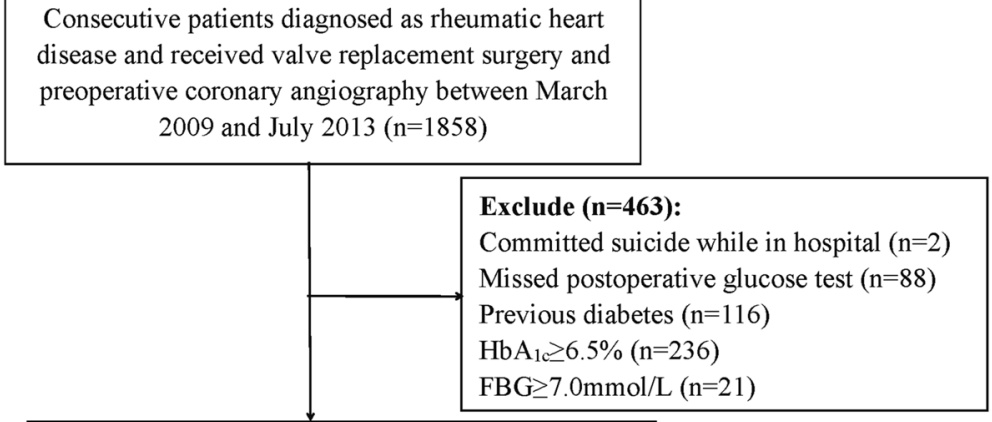

Included ( $n=1395)$ :

divided into four groups based on the quartiles

of postoperative glucose level

$<9.3(\mathrm{n}=348)$

9.3-10.9( $\mathrm{n}=354)$

$10.9-13.2(\mathrm{n}=341)$

$\geq 13.2(\mathrm{n}=352)$

Primary endpoint: in-hospital death

Secondary endpoint:

One-year mortality after operation

In-hospital MACEs

Fig. 1 Flowchart of the population screened 
telephone, and was recorded by trained nurses during the follow-up period.

\section{Data collection and follow-up}

Baseline clinical characteristics and laboratory data, inhospital mortality, and the type of surgery were collected. Blood samples for evaluating glucose levels were collected at admission to the intensive care unit (ICU) after operation. The FBG was measured by using an autoanalyzer (Roche AG, Basel, Switzerland). Other venous blood samples for laboratory analysis were collected in the next morning after admission to the ICU before operation. Follow-up data were obtained from interviewing patients, family members, or primary care physicians by telephone or clinical records of hospital readmissions or outpatient interviews for a period of one year after operation.

\section{Statistical analysis}

SPSS software version 13.0 (SPSS, Inc., Chicago, Illinois) was used for the analyses. Continuous data was presented as mean $\pm \mathrm{SD}$ or medians and interquartile ranges, then compared by the ANOVA or Wilcoxon rank-sum test accordingly. Categorical data was presented as percentage and compared by $x^{2}$ or fisher test. Variables whose $p$ value was less than 0.05 in univariate logistic regression analysis were included in the multivariable analysis. Kaplan-Meier curve analysis was performed to evaluated cumulative rate of one-year mortality and compared using the log-rank test. A value of $p<0.05$ was considered significant.

\section{Results}

\section{Patients' clinical characteristics}

Here, 1395 patients (female, 67.1\%; male, 32.9\%; age, $57 \pm 6$ years) were participated in this study, including 348 in Q1 group ( $<9.3 \mathrm{mmol} / \mathrm{L}), 354$ in Q2 group $(9.3-10.9 \mathrm{mmol} / \mathrm{L})$, 341 in Q3 group (10.9-13.2 mmol/L), and 352 in Q4 group $(\geq 13.2 \mathrm{mmol} / \mathrm{L})$ (Table 1). Patients with a high postoperative glucose level were significantly older $(56.3 \pm 5.7$ vs. $57.2 \pm 5.5$ vs. $57.5 \pm 5.7$ vs. $58.0 \pm 5.5, P=0.001)$ and were more likely female $(39.7 \%$ vs. $33.1 \%$ vs. $31.7 \%$ vs. $27.3 \%, P=$ 0.006). No significant differences were found among those 4 groups in the percentages of smoking, hypertension, mitral valve replacement, Tricuspid intervention, coronary artery bypass grafting (CABG), the level of serum creatinine, and Glycated hemoglobin. However, the percentages of NYHA $>$ II, and Aortic valve replacement, the level of FBG, and lg C-eactive protein (lgCRP) were significantly higher in patients with a high postoperative glucose. In addition, the rate of left ventricular ejection fraction (LVEF) was lower in those patients. $47(3.4 \%)$ patients died during the hospitalization, among which 4 (1.1\%) were in Q1, $8(2.3 \%)$ were in Q2, 6 (1.8\%) were in Q3, and $29(8.2 \%)$ were in Q4

Table 1 Patients' baseline characteristics

\begin{tabular}{|c|c|c|c|c|c|}
\hline \multirow[t]{2}{*}{ Clinical variables } & \multicolumn{5}{|c|}{ Postoperative BG level (mmol/L) } \\
\hline & Quartile $1(n=348)$ & Quartile $2(n=354)$ & Quartile $3(n=341)$ & Quartile $4(n=352)$ & $P$ \\
\hline Age (year) & $56.3 \pm 5.7$ & $57.2 \pm 5.5$ & $57.5 \pm 5.7$ & $58.0 \pm 5.5$ & 0.001 \\
\hline Males, n (\%) & $138(39.7)$ & $117(33.1)$ & $108(31.7)$ & $96(27.3)$ & 0.006 \\
\hline Smoking, n (\%) & $37(10.6)$ & $42(11.9)$ & $30(8.8)$ & $36(10.2)$ & 0.618 \\
\hline Hypertension, n (\%) & $29(8.3 \%)$ & $30(8.5)$ & $39(11.4)$ & $40(11.4)$ & 0.319 \\
\hline NYHA III-IV, n (\%) & $148(42.5)$ & $129(36.4)$ & $162(47.5)$ & $164(46.6)$ & 0.012 \\
\hline FBG (mmol/L) & $4.7 \pm 0.5$ & $4.8 \pm 0.6$ & $4.9 \pm 0.6$ & $4.9 \pm 0.6$ & $<0.001$ \\
\hline Postoperative glucose (mmol/L) & $8.1 \pm 1.0$ & $10.1 \pm 0.5$ & $12.0 \pm 0.7$ & $15.8 \pm 2.0$ & $<0.001$ \\
\hline Serum creatinine (umol/L) & $83.4 \pm 29.7$ & $78.6 \pm 22.3$ & $79.6 \pm 24.6$ & $81.5 \pm 25.7$ & 0.069 \\
\hline $\operatorname{lgCRP}(\mathrm{mg} / \mathrm{L})$ & $0.5 \pm 0.4$ & $0.5 \pm 0.4$ & $0.5 \pm 0.4$ & $0.6 \pm 0.4$ & 0.006 \\
\hline Glycated hemoglobin (\%) & $5.8 \pm 0.4$ & $5.8 \pm 0.4$ & $5.8 \pm 0.4$ & $5.8 \pm 0.4$ & 0.222 \\
\hline LVEF (\%) & $61.7 \pm 8.6$ & $62.1 \pm 8.6$ & $62.5 \pm 8.5$ & $60.7 \pm 10.3$ & 0.047 \\
\hline \multicolumn{6}{|l|}{ Type of surgery } \\
\hline Aortic valve replacement & $170(48.9)$ & $163(46.0)$ & $189(55.4)$ & $198(56.3)$ & 0.015 \\
\hline Mitral valve replacement & $331(95.1)$ & $318(95.5)$ & $314(92.1)$ & $326(92.6)$ & 0.174 \\
\hline Tricuspid intervention & $270(77.6)$ & $275(77.7)$ & $254(74.5)$ & $271(77.0)$ & 0.730 \\
\hline CABG & $13(3.7)$ & $12(3.4)$ & $14(4.1)$ & $20(5.7)$ & 0.445 \\
\hline In-hospital death & $4(1.1)$ & $8(2.3)$ & $6(1.8)$ & $29(8.2)$ & $<0.001$ \\
\hline In-hospital MACEs & $7(2.0)$ & $11(3.1)$ & $9(2.6)$ & $34(9.7)$ & $<0.001$ \\
\hline
\end{tabular}

NYHA New York Heart Association, FBG Fasting blood glucose, CRP C-reactive protein, LVEF Left ventricular ejection fraction, CABG Coronary artery bypass grafting, MACEs Major adverse clinical events 
$(\mathrm{P}<0.001)$. Furthermore, the incidence of in hospital MACEs $(2.0 \%$ vs. $3.1 \%$ vs. $2.6 \%$ vs. $9.7 \%, p<0.001)$ was significantly different among the four groups. Receiver operating characteristic (ROC) curve showed that postoperative $\mathrm{BG}>13.0$ $\mathrm{mmol} / \mathrm{L}$ was the best threshold for predicting in-hospital death, accompanying with a sensitivity of $61.7 \%$ and specificity of $76.9 \%$ (area under the curve (AUC) $=0.707,95 \%$ confidence interval (CI): 0.634-0.780, $P<0.001$, Fig. 2).

In the univariable logistic regression analysis, the postoperative $\mathrm{BG}>13.0 \mathrm{mmol} / \mathrm{L}$ was associated with in-hospital death (odds ratio $(\mathrm{OR})=4.666,95 \% \mathrm{CI}$ : $2.559-8.507, P<$ $0.001)$. The significant variables were age, NYHA III/IV, estimated glomerular filtration rate (eGFR) $<60 \mathrm{ml} / \mathrm{min} / 1.73$ $\mathrm{m} 2$, lgCRP, LVEF, TVR, and CABG. These variables were entered into a multiple logistic regression analysis, in which the results showed that postoperative $\mathrm{BG}>13.0 \mathrm{mmol} / \mathrm{L}$ remained an in- dependent predictor of in-hospital mortality (adjusted OR $=3.418,95 \%$ CI: $1.713-6.821 ; P<0.001$ ). In addition, it was revealed that the eGFR $<60 \mathrm{ml} / \mathrm{min} / 1.73$ $\mathrm{m} 2(\mathrm{OR}=2.952,95 \% \mathrm{CI}: 1.311-6.645, P=0.009)$ and TVR $(\mathrm{OR}=3.855,95 \% \mathrm{CI}: 1.127-3.52, P=0.032)$ were independently associated with in-hospital death (Table 2).

A total of 1248 (89.5\%) patients completed oneyear follow-up after surgery. However, during this period, 58 patients died. Result of Kaplan-Meier curve analysis is displayed in Fig. 3, illustrating the cumulative 1-year mortality among the four groups. The results suggested that the risk of death was increased for a postoperative $B G>13.2$ (log-rank 32.762, $P<0.001$ ) (Fig. 3).

\section{Discussion}

Our study revealed that high postoperative BG level was associated with increased morbidity and mortality in RHD patients undergoing VRS, while preoperative BG level was not associated with those factors.

The mechanism of how an elevated postoperative BG level was associated with mortality has not been still fully understood. Thus, the following aspects should be taken into account.

Firstly, body glucose levels are regulated by the endocrine system. Postoperative acute hyperglycemia is regarded as the body's stress response, and stress hyperglycemia complicated by cardiac surgery is clinically common, especially after cardiopulmonary bypass, the incidence rate reaches $95-100 \%$ [6]. Gandhi et al. suggested that when the BG level was greater than $100 \mathrm{mg} /$ $\mathrm{dl}$, the risk of various complications could be increased by $30 \%$ for every $20 \mathrm{mg} / \mathrm{dl}$ increase [7]. Thoracic surgery is a strong stimulus for the body, and when the variability of patient's BG level is considerable, it will aggravate the damage caused by such stress reaction, that is equivalent to a "second strike" effect [8].

On the one hand, hyperglycemia is always associated with hyperlactatemia $[9,10]$, increasing morbidity and mortality in acute critical illness $[11,12]$. A previous confirmed that

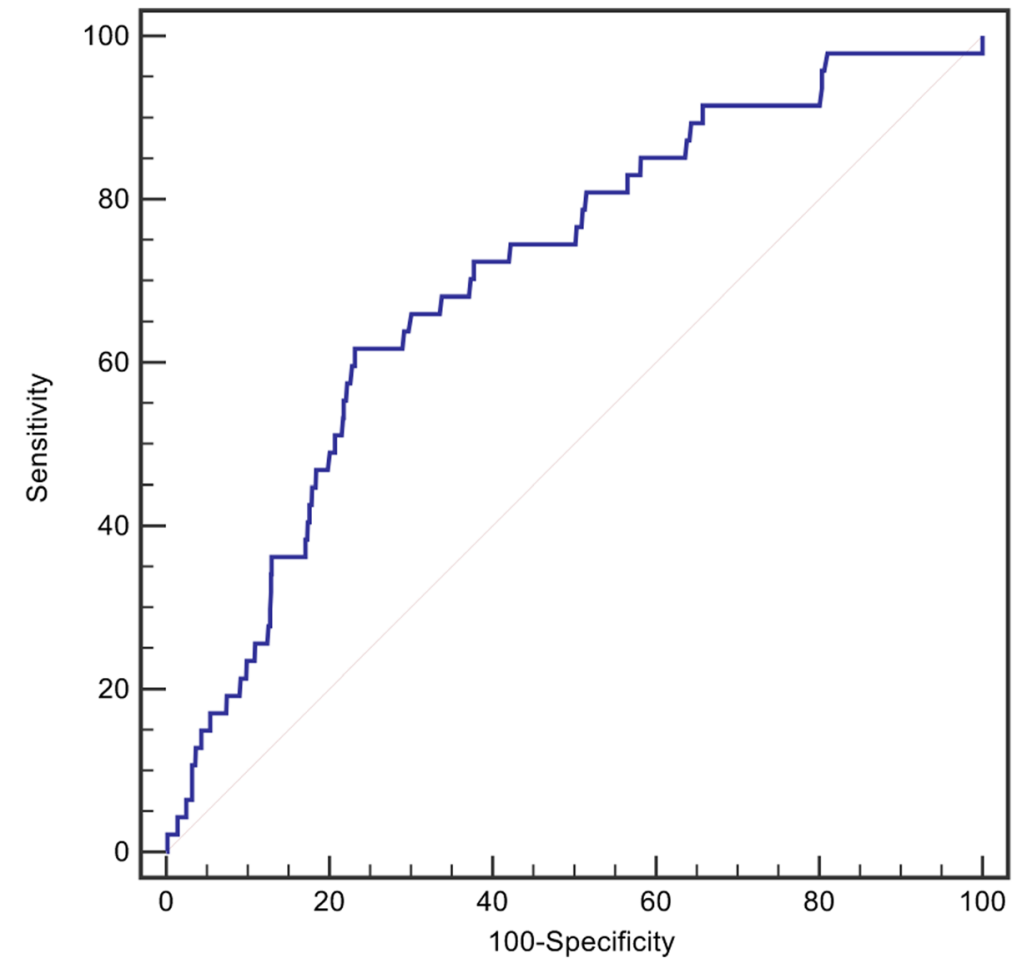

Fig. 2 Receiver operating characteristic (ROC) curve of postoperative blood glucose for in-hospital death 
Table 2 Univariate and multivariate logistic analyses for in-hospital death

\begin{tabular}{|c|c|c|c|c|c|c|}
\hline \multirow[t]{2}{*}{ Clinical variables } & \multicolumn{3}{|c|}{ Univariate Analysis } & \multicolumn{3}{|c|}{ Multivariate Analysis } \\
\hline & $\mathrm{OR}$ & $95 \% \mathrm{Cl}$ & $P$ & $\mathrm{OR}$ & $95 \% \mathrm{Cl}$ & $P$ \\
\hline Age & 1.1 .06 & $1.054,1.160$ & $<0.001$ & 1.056 & $0.994,1.122$ & 0.076 \\
\hline Female & 0.714 & $0.394,1.293$ & 0.266 & & & \\
\hline Smoking & 0.796 & $0.282,2.251$ & 0.668 & & & \\
\hline Hypertension & 1.348 & $0.562,3.235$ & 0.504 & & & \\
\hline NYHA III-IV & 1.981 & $1.095,3.583$ & 0.024 & 1.459 & $0.720,2.959$ & 2.95 \\
\hline FBG & 0.859 & $0.494,1.495$ & 0.592 & & & \\
\hline Postoperative BG > $13.0 \mathrm{mmol} / \mathrm{L}$ & 4.666 & $2.559,8.507$ & $<0.001$ & 3.418 & $1.713,6.821$ & $<0.001$ \\
\hline $\mathrm{eGFR}<60 \mathrm{ml} / \mathrm{min} / 1.73 \mathrm{~m}^{2}$ & 3.568 & $1.796,7.088$ & $<0.001$ & 2.952 & $1.311,6.645$ & 0.009 \\
\hline LgCRP & 3.580 & $1.751,7.321$ & $<0.001$ & 2.162 & $0.968,4.826$ & 0.060 \\
\hline \multicolumn{7}{|l|}{ Glycated hemoglobin } \\
\hline LVEF & 0.956 & $0.930,0.983$ & 0.001 & 0.973 & $0.942,1.004$ & 0.089 \\
\hline \multicolumn{7}{|l|}{ AVR } \\
\hline \multicolumn{7}{|l|}{ MVR } \\
\hline TVR & 2.615 & $1.026,6.665$ & 0.044 & 3.855 & $1.127,13.188$ & 0.032 \\
\hline CABG & 3.576 & $1.454,8.792$ & 0.006 & 2.821 & $0.869,9.156$ & 0.084 \\
\hline
\end{tabular}

NYHA New York Heart Association, eGFR estimated glomerular filtration rate, BG Blood glucose, CRP C-reactive protein, CABG Coronary artery bypass grafting

lactate levels might appropriately reflect the severity of disease and organ failure, and also were independently associated with short-term mortality in critically ill patients with liver cirrhosis [13]. Although anaerobic glycolysis increases the substrate, however, suppressing hyperglycemia generating 2,3-diphosphoglycerate, absolute insulin secretion, or relatively insufficient may lead to an increase in plasma free fatty acid concentration, and fatty acid can increase the myocardial oxygen consumption.
On the other hand, BG concentration can influence the function of immune system. The inflammatory response is closely associated with the prognosis of surgery and has been demonstrated in a large number of studies $[14,15]$. Studies have shown that inflammation affects wound healing and leads to an increase in postoperative mortality [16]. A variety of inflammatory mediators have also been shown as predictors of postoperative risk [17]. Researches have shown that plasma levels of interleukin

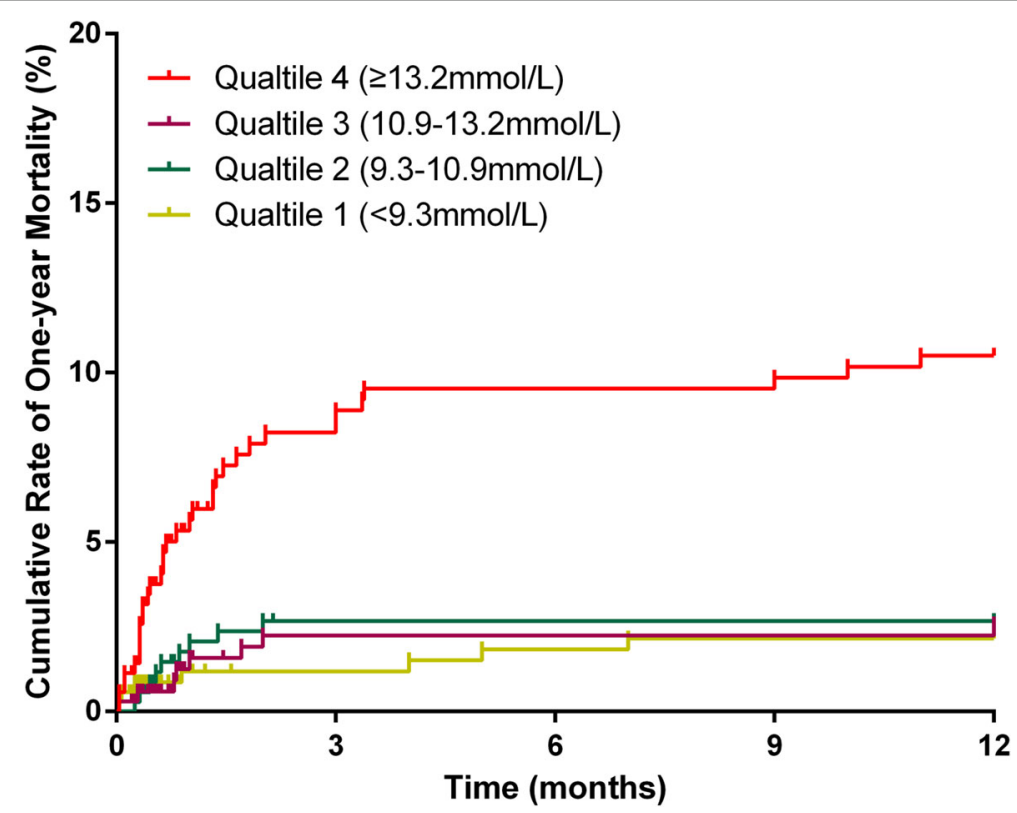

Fig. 3 Cumulative rate of 1-year mortality for patients in 4 different groups of postoperative blood glucose 
8 (IL-8) and C-reactive protein (CRP) are higher in patients with hyperglycemia than in patients with normal BG levels $[18,19]$, thereby reducing $\mathrm{T}$ cell expression and the body's immune response [20-22]. All the abovementioned reasons may explain that the immune response may be the cause of acute hyperglycemia, leading to a poor prognosis in patients undergoing cardiac surgery.

This study had some limitations. First, as this was a retrospective analysis based on prospectively collected data, some confounding might have affected the results. Second, the primary endpoint was all-cause mortality except for suicide which reduced the ability to fully evaluate the causes of death and consequently accurately compare the "cause of death" outcomes from this study with those of other populations.

\section{Conclusions}

In conclusion, we demonstrated that with the increase of postoperative BG, the prognosis of patients is worse. BG is able to accurately predict in-hospital death and mortality in patients with RHD after valve replacement surgery. Furthermore, we found that BG $>13.0 \mathrm{mmol} / \mathrm{L}$ is the optimum threshold for predicting in-hospital mortality.

\section{Abbreviation}

AUC: Area under the curve; BG: Blood glucose; CABG: Coronary artery bypass grafting; Cl: Confidence interval; CRP: C-reactive protein; eGFR: Estimated glomerular filtration rate; FBG: Fasting blood glucose; ICU: Intensive care unit; IL-8: Interleukin 8; LVEF: Left ventricular ejection fraction; MACEs: Major adverse clinical events; NYHA: New York heart association; OR: Odds ratio; RHD: Rheumatic heart disease; ROC: Receiver operating characteristic; VRS: Valve replacement surgery

\section{Acknowledgements}

None.

\section{Authors' contributions}

$L$ and NT contributed to the conception or design of the study. WZH, YW, XBW, DQY, CXZ and $\sqcup$ contributed to the acquisition, analysis, or interpretation of data. WZH and YW drafted the manuscript. $L J$ and $Y H J$ critically revised and polished the manuscript. All authors read and approved the final manuscript.

\section{Funding}

This study was supported by Science and Technology Planning Project of Guangzhou (grant no.grant no. 201903010005), Natural Science Foundation of Guangdong Province (grant no.2018A030313029) and National Natural Science Foundation (grant no. 81800262 and grant no.81670334). The funders had no role in the study design, data collection and analysis, decision to publish, or preparation of the manuscript. The work was not funded by any industry sponsors.

\section{Availability of data and materials}

the findings. The datasets used and/or analysed during the current study are available from the corresponding author on reasonable request.

\section{Ethics approval and consent to participate}

This study was a single-center retrospective study, so that the sample size was limited, which might inlude selection bias for publication: Not applicable.
Consent for publication

Not applicable.

\section{Competing interests}

The authors declare that they have no competing interests.

\section{Author details}

${ }^{1}$ Department of Cardiology, Guangdong Cardiovascular Institute, Guangdong Provincial People's Hospital, Guangdong Academy of Medical Sciences, Guangzhou 510080, China. ${ }^{2}$ Institute of Medical Sciences, School of Medical Sciences, University of Aberdeen, Foresterhill, Aberdeen, UK. ${ }^{3}$ Guangdong Provincial Geriatrics Institute, Guangdong Provincial People's Hospital, Guangdong Academy of Medical Sciences, Guangzhou 510080, China. ${ }^{4}$ School of Medicine, University of Alabama at Birmingham, Birmingham, AL, US.

Received: 21 August 2019 Accepted: 26 November 2019

Published online: 17 December 2019

\section{References}

1. Carapetis JR, Beaton A, Cunningham MW, et al. Acute rheumatic fever and rheumatic heart disease. Nature Rev Dis Primers. 2016;2:15084.

2. Carapetis JR, Steer AC, Mulholland EK, Weber MJLID. The global burden of group a streptococcal diseases. Lancet Infect Dis. 2005;5(11):685-94.

3. Atun R, Davies Jl, Gale EAM, et al. Diabetes in sub-Saharan Africa: from clinical care to health policy. Lancet Diab Endocrinol. 2017;5(8):622-67.

4. Huang Y, Cai X, Mai W, Li M, Hu Y. Association between prediabetes and risk of cardiovascular disease and all cause mortality: systematic review and meta-analysis. Bmj. 2016;355:i5953.

5. Ali Abdelhamid Y, Kar P, Finnis ME, Phillips LK, Plummer MP, Shaw JE, Horowitz M, Deane AM. Stress hyperglycaemia in critically ill patients and the subsequent risk of diabetes: a systematic review and meta-analysis. Critical care (London, England). 2016;20(1):301.

6. Hiesmayr MJ: Hyperglycemia and Outcome After Myocardial Infarction and Cardiac Surgery: So What?, In Seminars in cardiothoracic and vascular anesthesia 2006(Vol. 10, 3, 220-223). Thousand Oaks, CA: Sage Publications.

7. Gandhi GY, Nuttall GA, Abel MD, Mullany CJ, Schaff HV, Williams BA, Schrader LM, Rizza RA, McMahon MM. Intraoperative hyperglycemia and perioperative outcomes in cardiac surgery patients. Mayo Clin Proc. 2005; 80(7):862-6.

8. Capes SE, Hunt DK, Pathak P, HCJS G. Stress hyperglycemia and prognosis of stroke in nondiabetic and diabetic patients: a systematic overview. Stroke. 2001;32(10):2426.

9. Raper RF, Cameron G, Walker D, Bowey CJ. Type B lactic acidosis following cardiopulmonary bypass. Crit Care Med. 1997;25(1):46-51.

10. Maillet JM, Le Besnerais $P$, Cantoni M, Nataf $P$, Ruffenach A, Lessana A, Brodaty D. Frequency, risk factors, and outcome of hyperlactatemia after cardiac surgery. Chest. 2003;123(5):1361-6.

11. Kaukonen KM, Bailey M, Egi M, Orford N, Glassford NJ, Marik PE, Bellomo R. Stress hyperlactatemia modifies the relationship between stress hyperglycemia and outcome: a retrospective observational study. Crit Care Med. 2014;42(6):1379-85

12. Green JP, Berger T, Garg N, Horeczko T, Suarez A, Radeos MS, Hagar Y, Panacek EA. Hyperlactatemia affects the association of hyperglycemia with mortality in nondiabetic adults with sepsis. Acad Emerg Med Off J Soc Acad Emerg Med. 2012;19(11):1268-75.

13. Drolz A, Horvatits T, Rutter $K$, et al. Lactate improves prediction of shortterm mortality in critically ill cirrhosis patients: a multinational study. Hepatology. 2018;69(1):258.

14. Hu YF, Chen YJ, Lin YJ, Chen SA. Inflammation and the pathogenesis of atrial fibrillation. Nat Rev Cardiol. 2015;12(4):230-43.

15. Guo Y, Lip GY, Apostolakis S. Inflammation in atrial fibrillation. J Am Coll Cardiol. 2012;60(22):2263-70.

16. Agca R, Heslinga SC, van Halm VP, Nurmohamed MT. Atherosclerotic cardiovascular disease in patients with chronic inflammatory joint disorders. Heart. 2016;102(10):790-5.

17. Gonzalez-Gay MA, Gonzalez-Juanatey C. Cardiovascular risk factor assessment: still an unmet need in chronic inflammatory diseases. Heart. 2016;102(24):1937-9. 
18. Marfella R, Siniscalchi M, Esposito K, et al. Effects of stress hyperglycemia on acute myocardial infarction: role of inflammatory immune process in functional cardiac outcome. Diabetes Care. 2003;26(11):3129-35.

19. Gandhi GY, Nuttall GA, Abel MD, et al. Intensive intraoperative insulin therapy versus conventional glucose management during cardiac surgery: a randomized trial. Ann Intern Med. 2007;146(4):233-43.

20. Macintyre AN, Gerriets VA, Nichols AG, et al. The glucose transporter Glut1 is selectively essential for CD4 T cell activation and effector function. Cell Metab. 2014;20(1):61-72.

21. Kishton RJ, Sukumar M, Restifo NP. Metabolic regulation of T cell longevity and function in tumor immunotherapy. Cell Metab. 2017;26(1):94-109.

22. Thaiss CA, Levy M, Grosheva I, et al. Hyperglycemia drives intestinal barrier dysfunction and risk for enteric infection. Science (New York, NY). 2018; 359(6382):1376-83

\section{Publisher's Note}

Springer Nature remains neutral with regard to jurisdictional claims in published maps and institutional affiliations.

Ready to submit your research? Choose BMC and benefit from:

- fast, convenient online submission

- thorough peer review by experienced researchers in your field

- rapid publication on acceptance

- support for research data, including large and complex data types

- gold Open Access which fosters wider collaboration and increased citations

- maximum visibility for your research: over $100 \mathrm{M}$ website views per year

At $B M C$, research is always in progress.

Learn more biomedcentral.com/submissions 